\title{
Effect of an abrupt switch from a milk-based to a fibre-based diet on gastric emptying rates in pigs: difference between origins of fibre
}

\author{
Gaëlle Boudry*, Sylvie Guérin and Charles Henri Malbert \\ INRA-UMRVP, St-Gilles, France \\ (Received 15 November 2003 - Revised 28 May 2004 - Accepted 27 July 2004)
}

\begin{abstract}
A characteristic dietary feature at weaning is a switch from a milk-based to plant-based diet, i.e. from a non-fibrous to a fibrous diet. The present study aimed to evaluate the effects of such an abrupt dietary switch on gastric emptying rate in pigs maintained on a milk substitute after weaning. Eighteen piglets were kept on a milk substitute for 5 weeks after weaning and were then switched to wheat-based or barleybased diets or kept on the milk substitute (six piglets per group). All piglets were fasted for $1 \mathrm{~d}$ before the switch and daily food intake was then increased linearly to reach initial values within $3 \mathrm{~d}$. The gastric emptying rate was measured by $\gamma$-scintigraphy before and after the switch. Corpo-antral peristalsis was also evaluated by the use of high-frequency scintigraphic frames. The gastric emptying rate of the wheat-based diet was accelerated on days 1 to 3 after the switch, but was similar to that in the milk-substitute group thereafter. This acceleration was concomitant with an enhanced frequency of corpo-antral waves on days 2 and 3. Conversely, the gastric emptying rate of the barley-based diet tended to be enhanced on day 2, but was delayed on days 4 and 5, without any change in frequency of corpo-antral waves. We conclude that a switch from a non-fibrous to a fibrous diet alters the gastric emptying rate differently depending on the type of dietary fibre.
\end{abstract}

Gastric emptying: Weaning: Barley: Wheat: Antral peristalsis: $\gamma$-Scintigraphy

The gastric emptying rate is a key factor in the control of food intake. It conditions the degree of distension of the stomach wall, a variable known to alter food intake (Lepionka et al. 1997). It also conditions the release of nutrients in the duodenum, which in turn releases satiety hormones such as cholecystokinin (Bray, 2002). In addition, the gastric emptying rate can be linked to health status. Indeed, delayed or increased gastric emptying rates have been reported in patients with diarrhoea (Levine, 1986; Feurle, 1987; Parr et al. 1988; Galil et al. 1993; Charles et al. 1997). An adequate gastric emptying rate is therefore a critical variable in achieving maximal expression of growing capacities of animals and in preserving their health status.

Gastric emptying is a highly controlled mechanism, dependent on the physical and chemical characteristics of the gastric contents (Mayer et al. 1994). A change in the chemical characteristics of the meal leads to adaptation of gastric emptying, with different time patterns depending on the nutrient considered. Consumption of a high-fat or high-protein diet for 2 weeks increased the gastric emptying rate of a high-fat or high-protein test meal respectively in a nutrient specific way (Cunningham et al. 1991a; Shi et al. 1997; Covasa \& Ritter 2000; Castiglione et al. 2002). The same phenomenon was observed with carbohydrate, but in $3 \mathrm{~d}$ (Cunningham et al. 1991b).
Dietary switches occur several times during the lives of animals in intensive production systems, such as pig production. One of the most dramatic switches occurs at weaning, when piglets abruptly switch from sows' milk to a complex plant-based diet. This dietary switch is characterized by a switch from a high-fat and low-carbohydrate diet to a low-fat and high-carbohydrate diet, concomitant with a switch from a non-fibrous to a fibrous diet (Etienne et al. 2000). This switch is associated with a growth check, anorexia and diarrhoea during the first post-weaning diets (Madec et al. 1998). The role of different types of fibre on gastric emptying has already been investigated (Rydning et al. 1985; McIntyre et al. 1997; Guerin et al. 2001), but the effect of an abrupt switch from a non-fibrous to a fibrous diet is not known. The aim of the present study was therefore to investigate the short-term effect of an abrupt switch from a milk substitute to cereal-based diets in animals that had been weaned on a milk substitute. Two different types of cereals, whose fibres have different characteristics, were used (barley and wheat; Englyst $e t$ al. 1989). A reduction in food intake was also imposed in all groups to mimic temporary anorexia, as observed at weaning. The gastric emptying rate was measured non-invasively using $\gamma$-scintigraphy before and after the dietary switch. Corpo-antral peristalsis was also evaluated by high-frequency scintigraphy imaging. 


\section{Materials and methods}

Diets

Three diets with approximately the same macronutrient proportions but originating from different dietary sources were used: a milk substitute, and wheat-based and barley-based diets (Table 1). The milk substitute contained no plant products except for purified maltodextrin and vegetable oil. The wheat-based and barley-based diets were formulated to maximize the incorporation of plant-based products. Synthetic amino acids were used to balance the amino acid:energy ratios. Diets were offered as a mash $(450 \mathrm{~g} \mathrm{DM} / \mathrm{kg})$ irrespective of the diet. Wheat and barley were ground on a $1.8 \mathrm{~mm}$ sieve.

Measurement of the water-holding capacity (WHC) of the two cereal-based diets was adapted from the centrifugation method of Johansen et al. (1996). Briefly, diets were prepared as fed, left for $1 \mathrm{~h}$ at room temperature and then centrifuged at $4000 \mathrm{rpm}$ for $20 \mathrm{~min}$ at room temperature. The supernatant fraction was removed by suction and the sediment dried at $70^{\circ} \mathrm{C}$ for $48 \mathrm{~h}$. The WHC was calculated from the amount of water retained in the sediment and removed by the drying procedure.

Trials to evaluate the coagulation properties of the milk substitute were done as described by Hurtaud et al. (1993). There was no sign of coagulation, but a slight thickening was observed, probably due to maltodextrin swelling.

Table 1. Composition of diets

\begin{tabular}{|c|c|c|c|}
\hline & \multicolumn{3}{|c|}{ Diet } \\
\hline & Milk substitute & Wheat & Barley \\
\hline \multicolumn{4}{|l|}{ Ingredients ( $\mathrm{g} / \mathrm{kg}$ as fed) } \\
\hline Skimmed milk powder & 260 & - & - \\
\hline Wheat & - & 805 & - \\
\hline Barley & - & - & $858 \cdot 6$ \\
\hline Maltodextrin & 595.5 & 50 & - \\
\hline $\begin{array}{l}\text { Soluble fish protein } \\
\text { concentrate }\end{array}$ & 92 & 92 & 92 \\
\hline Vegetable oil & 10 & - & - \\
\hline $\begin{array}{l}\text { Vitamin-mineral } \\
\text { mixture }\end{array}$ & 5 & 5 & 5 \\
\hline $\mathrm{CaCO}_{3}$ & 10 & 17 & 18 \\
\hline $\mathrm{CaHPO}_{4} \cdot 2 \mathrm{H}_{2} \mathrm{O}$ & 25 & 25 & 23 \\
\hline $\mathrm{NaHCO}_{3}$ & - & 3 & 3 \\
\hline L-Lys & - & $2 \cdot 2$ & 0.4 \\
\hline DL-Met & 1.9 & - & - \\
\hline L-Trp & 0.6 & $0 \cdot 1$ & - \\
\hline L-Thr & - & 0.7 & - \\
\hline \multicolumn{4}{|l|}{ Chemical composition } \\
\hline $\mathrm{DM}(\mathrm{g} / \mathrm{kg})$ & 911 & 874 & 884 \\
\hline $\begin{array}{l}\text { Crude protein } \\
(\mathrm{N} \times 6 \cdot 25, \mathrm{~g} / \mathrm{kg} \mathrm{DM})\end{array}$ & 179 & 176 & 177 \\
\hline Crude fat (g/kg DM) & 34 & 29 & 29 \\
\hline Total dietary fibre $(\mathrm{g} / \mathrm{kg})$ & 0 & 124 & 165 \\
\hline Net energy (MJ/kg DM)* & $9 \cdot 88$ & 9.50 & 8.69 \\
\hline $\mathrm{Ca}(\mathrm{g} / \mathrm{kg} \mathrm{DM}) \dagger$ & $14 \cdot 5$ & $14 \cdot 9$ & $14 \cdot 7$ \\
\hline $\mathrm{Na}(\mathrm{g} / \mathrm{kg} \mathrm{DM}) \dagger$ & $2 \cdot 2$ & $2 \cdot 1$ & $2 \cdot 1$ \\
\hline $\mathrm{Cl}(\mathrm{g} / \mathrm{kg} \mathrm{DM}) \dagger$ & $3 \cdot 3$ & $2 \cdot 2$ & $2 \cdot 6$ \\
\hline $\mathrm{K}(\mathrm{g} / \mathrm{kg} \mathrm{DM}) \dagger$ & $4 \cdot 7$ & $3 \cdot 7$ & $4 \cdot 7$ \\
\hline$P(g / k g ~ D M) \dagger$ & $10 \cdot 0$ & $10 \cdot 5$ & $10 \cdot 2$ \\
\hline $\mathrm{WHC}(\mathrm{g} / \mathrm{g})$ & ND & 0.68 & 1.01 \\
\hline
\end{tabular}

WHC, water-holding capacity.

* Calculated from digestible energy and elemental analysis.

†Estimated from tables (Noblet et al. 1989).
The physical properties of this milk substitute did not resemble those of sows' milk (mainly in term of viscosity), but unlike pure cows' milk, previous observations showed that gastric emptying rate of this type of diet resembles that of sows' milk in 10-d-old piglets (Sève et al. 1975).

\section{Experimental protocol}

Eighteen female Large White $\times$ Landrace crossbred piglets were weaned at 4 weeks old and housed in individual cages. They were fed twice per d with $100 \mathrm{~g}$ milk substitute/kg body weight ${ }^{0.75}$ for 5 weeks. Body weight was measured weekly and the feeding schedule was then adjusted according to the expected growth. Water was available ad libitum.

Five weeks after weaning, one-third of the piglets was switched to the wheat-based diet, one-third to the barleybased diet, and one-third was maintained on the milk substitute. Daily energy intake during the dietary transition was identical for the three groups: $100 \mathrm{~g}$ milk substitute/ $\mathrm{kg}$ body weight ${ }^{0.75}$ on day -1 ; fasting on day $0 ; 33,67$, 100,100 and $100 \mathrm{~g} / \mathrm{kg}$ body weight ${ }^{0 \cdot 75}$ on days 1 to 5 respectively.

Every day, starting at day -1 and with the exception of day 0 (fasting day), gastric emptying and motility were evaluated by $\gamma$-scintigraphic imaging after ingestion of a test meal of $250 \mathrm{~g} \mathrm{DM}$. The duration of test meal ingestion was not fixed, since some animals had difficulty in ingesting a feed that was entirely new to them within a short amount of time. A second meal was given in the afternoon after the experiment to complete the scheduled daily food intake.

\section{Labelling of test meals}

The difference in the chemical nature of the diets made it difficult to label a specific component of the meal. Therefore, we labelled egg albumin and incorporated it within the three diets. Two egg whites labelled with freshly made ${ }^{99 \mathrm{~m}} \mathrm{Tc}$ colloid $(70 \mathrm{MBq}$; TCK 1, CISBio International, Fontenay aux Roses, France) were incorporated into the test meals (250 g milk substitute, barley-based diet or wheat-based diet mixed with $310 \mathrm{ml}$ water). The volumes of the test meals were similar $(525 \mathrm{ml}$ for the milk substitute and barley-based diet and $520 \mathrm{ml}$ for the wheat-based diet).

To evaluate the quality of the labelling, $10 \mathrm{~g}$ labelled meal was dissolved in $50 \mathrm{ml}$ saline $(9 \mathrm{~g} \mathrm{NaCl} / \mathrm{l})-2$ $\mathrm{M}-\mathrm{HCl}$ and pepsin (Sigma, St Quentin Fallavier, France). The mixture was incubated for $60 \mathrm{~min}$ at $38^{\circ} \mathrm{C}$ in test vials. Test vials were then centrifuged $(4000 \mathrm{rpm}, 5 \mathrm{~min})$ and placed under the $\gamma$-camera head for static acquisition lasting $5 \mathrm{~min}$. The amount of radioactivity was measured in two regions of interest representing the supernatant fraction and the sediment. The ratio between the counts obtained in the two regions was calculated. The experiments were performed in triplicate for each meal. The sediment fraction of the milk substitute, wheat-based diet and barley-based diet contained 95.1 (SEM 0.6), 82.7 (SEM 0.3 ) and 86.5 (SEM 0.7) \% of the radioactivity respectively, indicating the adequacy of the meal labelling with egg albumin. 


\section{Scintigraphic data acquisition and analysis}

Pigs were trained to stand quietly in a sling allowing approximately $200 \mathrm{~mm}$ movement in each direction. The sling was designed to allow the pig to stand for prolonged periods. To cancel animal motion relative to the camera head, a $50 \mathrm{~mm}$ square sticker with one drop of ${ }^{99 \mathrm{~m}} \mathrm{Tc}$ (about $5 \mathrm{MBq}$ ) was placed extemporaneously on the left flank of the animal alongside the area projection of the stomach and served as fiduciary point during analysis. Test meals were consumed spontaneously with the animal standing laterally to the head of the $\gamma$-camera.

Data were acquired for $120 \mathrm{~min}$, starting at the beginning of meal ingestion, as $64 \times 64$ pixels matrix size using a computerized scintillation camera (Apex 900; Elscint, Aifa, Israel) fitted with a high-resolution-low-energy collimator. Frames $(6 \mathrm{~s})$ were acquired every $2 \mathrm{~min}$ for the entire duration of the study, except from the twentieth to the thirtieth minutes, during which images were acquired at $3 \mathrm{~s}$ intervals. This $10 \mathrm{~min}$ period of high-frequency acquisition served as the gastric motility measurement. Once the acquisition was completed, two sets of data were built up: a low-frequency set for gastric emptying quantification and a high-frequency set for motility measurement.

The choice of the twentieth to the thirtieth minute timeslot for high-frequency data acquisition was for technical reasons. Indeed, in order to get a good image resolution, the quantity of radioactivity present in the stomach needs to be sufficient. The protocol cannot be performed at the end of the gastric emptying study, as the radioactivity remaining in the stomach would have been too low. On the other hand, the quality of the images also depends on the quietness of the animal. The animals are usually not quiet at the beginning of the recording due to their manipulation before the experiment. We therefore chose the twentieth to the thirtieth minute arbitrarily as a compromise between the quietness of the animal and a sufficient amount of radioactivity remaining in the stomach.

Total and proximal emptying curves were calculated according to published procedures (Blat et al. 2001; Guerin et al. 2001). To correct for different meal ingestion times, time measurements were referenced to the minute when the radioactivity in the region of interest was maximum. Emptying curves (expressed as percentage of isotope $v$. time) were derived from total and proximal stomach regions of interest. Emptying curves were fitted to a power exponential function (Elashoff et al. 1982) to calculate half-emptying time $\left(t_{1 / 2}\right)$ and curve shape $(\beta)$. Emptying curves with a loose fitting to the power exponential model indicated by a mean square error $>0.005$ for the total stomach and $>0.01$ for the proximal stomach were not taken into account in the analyses. Finally, the isotope fractions remaining in the stomach at $t 25,50,150$ and $250 \mathrm{~min}$ were calculated from the exponential model parameters for the total stomach.

Evaluation of corpo-antral peristalsis was performed using the method described by Linke et al. (2000) in human subjects and adapted to the pig. Briefly, a functional image representing the motion of gastric contents was built for the entire $10 \mathrm{~min}$ period of high-frequency acquisition.
Each column of the functional image corresponded to one acquired image, i.e. $3 \mathrm{~s}$. Each pixel of this column represented the sum of all pixels contained within a row of the area of interest of the gastric shape. Before construction of the functional image, acquired images were automatically aligned to cancel animal motion artefacts using the fiduciary point as a reference for $\mathrm{XY}$ translations. The visual resolution of the functional image was thereafter enhanced by the 'nearest neighbour extrapolation' method with a factor of one to ten and the contrast between edges intensified by a Laplacian filter. Evaluation of the mean frequency of propagated corpo-antral contractions over the whole $10 \mathrm{~min}$ period was performed in the frequency domain of the functional image to reduce observer bias. The whole functional image was fast Fourier transformed and the frequency with the maximal amplitude selected as the mean contraction frequency for the motility measurement period.

\section{Statistical analysis}

ANOVA was performed using the General Linear Model of SAS (SAS Institute Inc., Cary, NC, USA), which is an ANOVA procedure best fitted for unbalanced situations with unequal number of observations for the different groups. The explaining variables included diet, animal within diet, day, and day $\times$ diet. Meal ingestion duration was also included as a co-variable, since there was significant difference between diets for this variable. For each day, wheat-based- and barley-based-diet groups were compared with the milk-substitute group using the Bonferroni post hoc multiple comparison approximation.

Results are expressed as least square mean values with their standard errors. A $P$ value $<0.05$ was considered significant in all analyses, but tendencies with $P<0.08$ are also indicated.

\section{Results}

\section{Duration of meal ingestion}

The duration of test meal ingestion was greater on day 1 for wheat-fed pigs compared with milk substitute-fed pigs (236 (SEM 28) v. 68 (SEM 28) s; $P<0.05)$, but there was no longer a difference thereafter. Conversely, duration of barley-based meal ingestion was significantly longer than milk-substitute meals during the $5 \mathrm{~d}$ following the dietary switch (s): day 1, 338 (SEM 32) v. 68 (SEM 28); day 2, 237 (SEM 28) v. 59 (SEM 28); day 3, 164 (SEM 28) v. 70 (SEM 28) s; day 4, 165 (SEM 32) v. 65 (SEM 23); day $5,165($ SEM 32) v. 65 (SEM 28); $P<0.05$ for each of the $5 \mathrm{~d}$.

\section{Effect of the dietary switch from milk substitute to cereal-} based diet on the gastric emptying rate

Changes in gastric emptying rates after the switch differed depending on the origin of the dietary fibre. When analysing the estimated amount of radioactivity remaining 25 , 50,150 and $250 \mathrm{~min}$ after the beginning of the meal, we observed that the gastric emptying rate of the wheatbased diet was hastened from day 1 to day 3 compared 
with the milk substitute, and then became similar to that of the milk substitute for days 4 and 5 (Fig. 1). On the other hand, gastric emptying of the barley-based diet was also hastened on day 2 , similar to that of the milk substitute on day 3, and was then delayed on days 4 and 5 (Fig. 1). Similar changes were observed for $t_{1 / 2}$ values, although these did not always reach statistical significance (Table 2). Moreover, gastric-emptying curve profiles were altered by the dietary switch. On day 5 (with the same tendency on days 3 and 4 ), $\beta$ values were lower with the barley-based diet than the milk substitute, indicating that on these days, gastric emptying was rapid at the beginning of emptying, but then slowed down while emptying progressed (Table 2). No lag-phase was observed for any of the emptying curves.

(A)

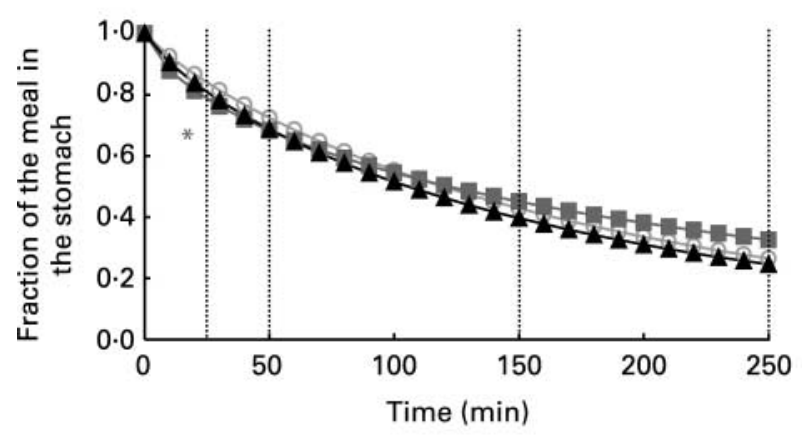

(C)

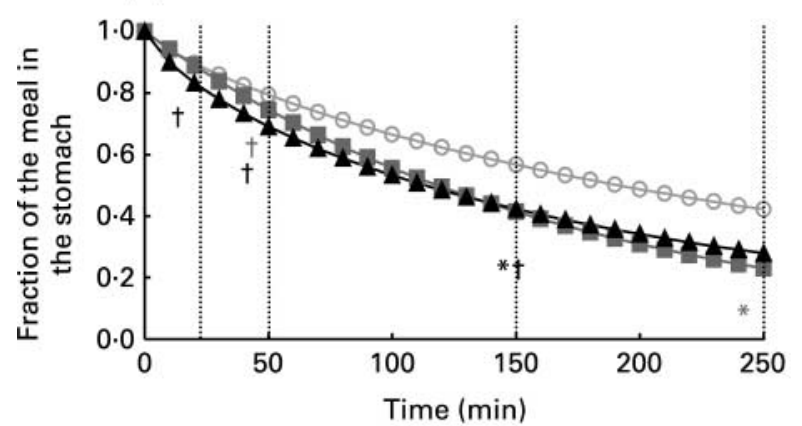

(E)

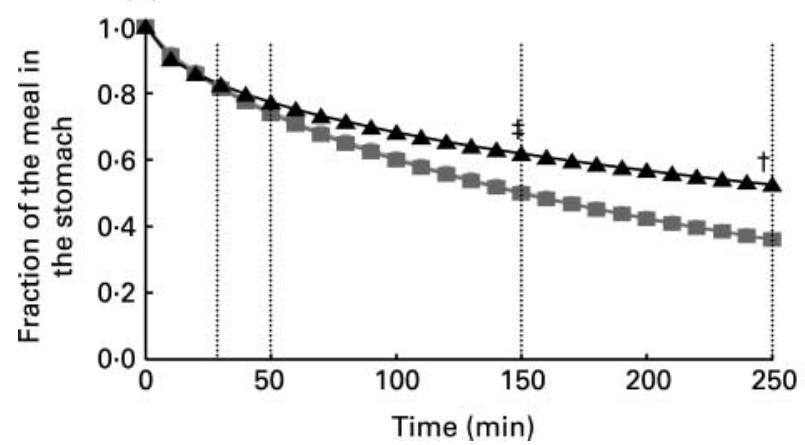

Effect of the dietary switch from milk substitute to cerealbased diet on the emptying rate of the proximal stomach

No differences between diets were observed regarding the emptying curve parameters $\left(t_{1 / 2}\right.$ and $\beta$ ) of the proximal stomach (Table 3).

Effect of the dietary switch from milk substitute to cerealbased diet on the corpo-antral contractions

The frequency of corpo-antral contractions during the twentieth to thirtieth minute period was significantly higher $(P<0.05)$ with the wheat-based diet on days 2 and 3 (with the same tendency on day $1, P=0.08$ ) compared with the milk substitute (Figs 2 and 3). No change was observed for the barley-based diet (Fig. 2).

(B)

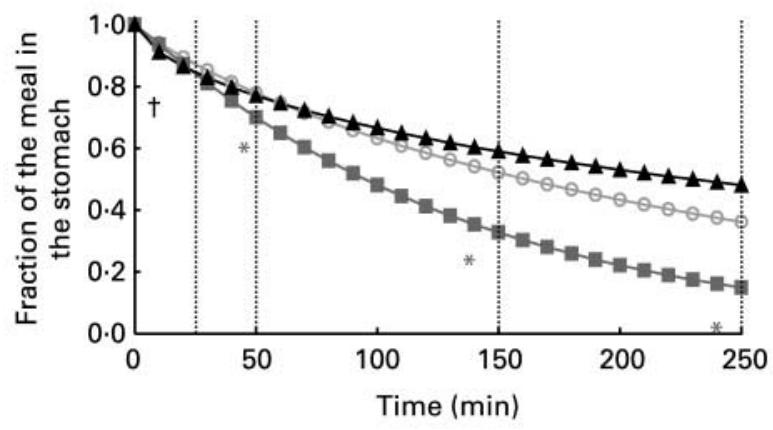

(D)

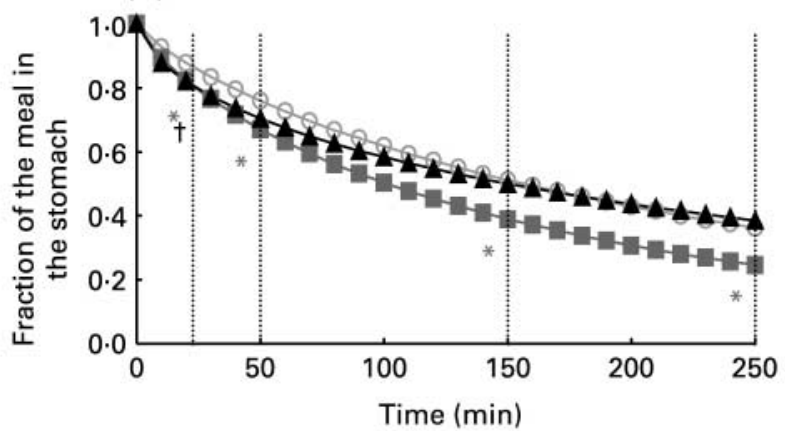

(F)

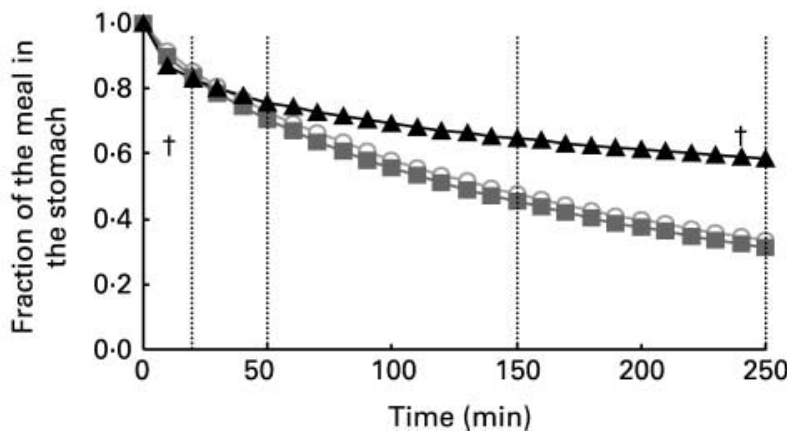

Fig. 1. Gastric emptying profiles during the dietary transition. (A), day -1; (B), day 1; (C), day 2; (D), day 3; (E), day 4; (F), day 5. O, Milk-substitute group; 1 , wheat-based-diet group; $\boldsymbol{\Lambda}$, barley-based-diet group. Curves were obtained from the mean gastric emptying time $\left(t_{1 / 2}\right)$ and shape of the emptying curve $(\beta)$ for each dietary group. For details of diets and procedures, see Table 1 and p. 914. Values are least square means. The gastric emptying rate of the wheat-based diet was accelerated on days 1 to 3 but returned to values similar to those of the milksubstitute group on days 4 and 5 . Conversely, the gastric emptying rate of the barley-based diet was accelerated on day 2 but delayed on days 4 and 5 . Mean values for the fraction of the meal present in the stomach were significantly different from those of the milk-substitute group: ${ }^{*} P<0.05$ (wheat-based-diet group), $† P<0.05$ (barley-based-diet group). Mean values tended towards being significantly different from those of the milk-substitute group: $\ddagger P<0.08$. 
Table 2. Gastric half-emptying time $\left(t_{1 / 2}\right)$ and shape of the emptying curve $(\beta)$ during the dietary switch $\ddagger$ (Least square mean values with their standard errors for six pigs per group)

\begin{tabular}{|c|c|c|c|c|c|c|c|c|c|c|c|c|}
\hline \multirow{4}{*}{$\begin{array}{l}\text { Diet... } \\
\text { Day }\end{array}$} & \multicolumn{12}{|c|}{ Total stomach } \\
\hline & \multicolumn{6}{|c|}{$t_{1 / 2}(\min )$} & \multicolumn{6}{|c|}{$\beta$} \\
\hline & \multicolumn{2}{|c|}{ Milk substitute } & \multicolumn{2}{|c|}{ Wheat } & \multicolumn{2}{|c|}{ Barley } & \multicolumn{2}{|c|}{ Milk substitute } & \multicolumn{2}{|c|}{ Wheat } & \multicolumn{2}{|c|}{ Barley } \\
\hline & Mean & SEM & Mean & SEM & Mean & SEM & Mean & SEM & Mean & SEM & Mean & SEM \\
\hline-1 & 119 & 48 & 122 & 48 & 106 & 48 & 0.88 & 0.07 & $0.67^{\star}$ & 0.07 & 0.82 & 0.07 \\
\hline 1 & 161 & 49 & 95 & 53 & 229 & 68 & 0.87 & 0.07 & 1.04 & 0.08 & 0.64 & 0.11 \\
\hline 2 & 191 & 49 & 118 & 48 & 113 & 53 & 0.82 & 0.07 & 1.00 & 0.07 & 0.77 & 0.08 \\
\hline 3 & 157 & 49 & 101 & 48 & 150 & 48 & 0.81 & 0.07 & 0.78 & 0.07 & $0.62 \dagger$ & 0.07 \\
\hline 4 & 152 & 49 & 149 & 48 & $285 \dagger$ & 54 & 0.77 & 0.07 & 0.75 & 0.07 & $0.57 \dagger$ & 0.08 \\
\hline 5 & 138 & 49 & 125 & 48 & $470^{\star}$ & 54 & 0.77 & 0.07 & 0.74 & 0.07 & $0.41^{\star}$ & 0.08 \\
\hline
\end{tabular}

Mean values were significantly different from those of the milk-substitute group: ${ }^{\star} P<0.05$.

Mean values had a tendency towards a significant difference from those of the milk-substitute group: $† P<0.08$. $\ddagger$ For details of diets and procedures, see Table 1 and p. 914.

Table 3. Half-emptying time $\left(t_{1 / 2}\right)$ and shape of the emptying curve $(\beta)$ of the proximal stomach during the dietary switch $\dagger$ (Least square mean values with their standard errors for six pigs per group)

\begin{tabular}{|c|c|c|c|c|c|c|c|c|c|c|c|c|}
\hline \multirow{4}{*}{$\begin{array}{l}\text { Diet... } \\
\text { Day }\end{array}$} & \multicolumn{12}{|c|}{ Proximal stomach } \\
\hline & \multicolumn{6}{|c|}{$t_{1 / 2}(\min )$} & \multicolumn{6}{|c|}{$\beta$} \\
\hline & \multicolumn{2}{|c|}{ Milk substitute } & \multicolumn{2}{|c|}{ Wheat } & \multicolumn{2}{|c|}{ Barley } & \multicolumn{2}{|c|}{ Milk substitute } & \multicolumn{2}{|c|}{ Wheat } & \multicolumn{2}{|c|}{ Barley } \\
\hline & Mean & SEM & Mean & SEM & Mean & SEM & Mean & SEM & Mean & SEM & Mean & SEM \\
\hline-1 & 43 & 11 & 35 & 10 & 43 & 12 & 0.67 & 0.11 & 0.62 & 0.10 & 0.65 & 0.13 \\
\hline 1 & 40 & 10 & 39 & 11 & 52 & 23 & 0.76 & 0.10 & 0.97 & 0.12 & 0.63 & 0.24 \\
\hline 2 & 58 & 10 & 37 & 12 & 41 & 12 & 0.67 & 0.10 & 0.86 & 0.13 & 0.75 & 0.13 \\
\hline 3 & 41 & 11 & 38 & 12 & $80^{*}$ & 10 & 0.71 & 0.11 & 0.85 & 0.13 & 0.60 & $0 \cdot 10$ \\
\hline 4 & 51 & 12 & 36 & 11 & 64 & 11 & 0.66 & 0.13 & 0.74 & 0.11 & 0.55 & 0.11 \\
\hline 5 & 42 & 12 & 42 & 10 & 50 & 12 & 0.72 & 0.13 & 0.82 & 0.10 & 0.68 & 0.13 \\
\hline
\end{tabular}

Mean value was significantly different from that of the milk-substitute group: ${ }^{\star} P<0.05$.

†For details of diets and procedures, see Table 1 and p. 914.

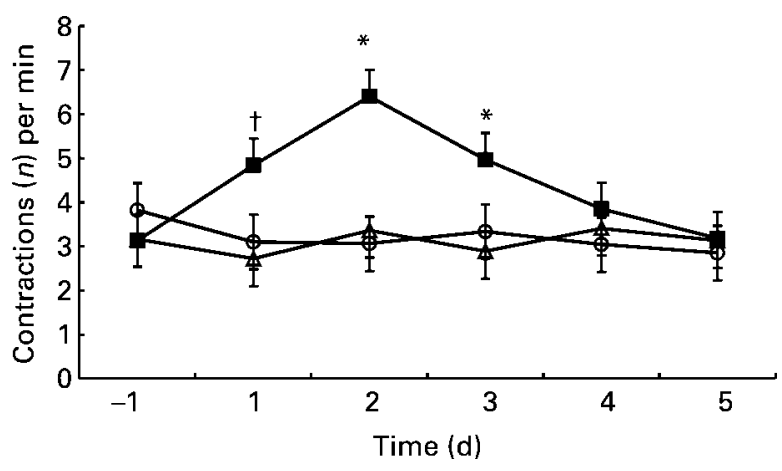

Fig. 2. Frequencies of corpo-antral contractions from the twentieth to the thirtieth minute after the meal during the dietary transition. $\bigcirc$, Milk-substitute group; $\mathbf{\square}$, wheat-based-diet group; $\triangle$, barley-based-diet group. For details of diets and procedures, see Table 1 and p. 914. The frequency of contractions tended to be enhanced on day 1 and was enhanced on days 2 and 3 with the wheat-based diet compared with the milk substitute. Values are least square means with their standard errors shown by vertical bars. Mean values were significantly different from those of the milk-substitute group: ${ }^{\star} P<0 \cdot 05$. Mean value tended towards being significantly different from that of the milk-substitute group: $\dagger P<0.08$.

\section{Discussion}

We have demonstrated that a dietary switch from milk substitute to a cereal-based diet induced different gastric emptying alterations depending on the type of cereal. Whereas the gastric emptying rate of the wheat-based diet was accelerated on the first days following the switch and then came back to normal, gastric emptying rate for the barley-based diet had a 'double behaviour': accelerated on day 2 but delayed on days 4 and 5 . These differences between diets were not correlated to impaired proximal emptying, but could be partly explained by changes in corpo-antral peristalsis.

The aim of the present study was to focus on the effect of a switch from a non-fibrous to a fibrous diet on the gastric emptying rate. Therefore, special care had to be taken to conserve the physical characteristics and the macronutrient proportions in the three different meals. Differences in protein and fat concentrations cannot explain the differences in gastric emptying observed, since the meals were formulated to have approximately the same composition of those macronutrients. Moreover, differences in the gastric emptying rate could not be accounted for by 
(A)

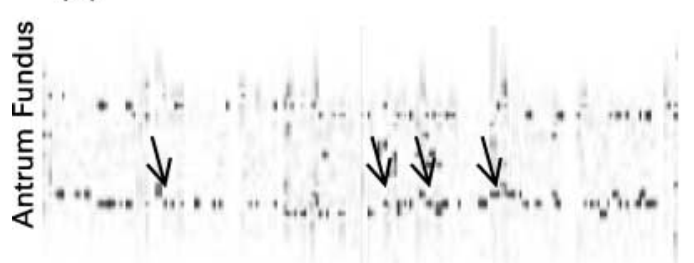

(B)

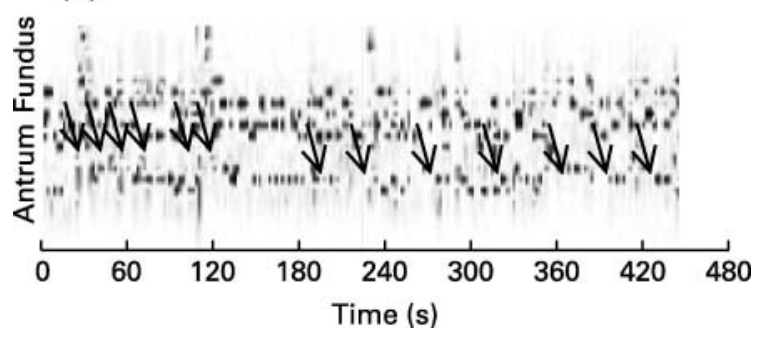

Fig. 3. Typical examples of functional images obtained from the high-frequency frames acquisition from the twentieth to the thirtieth minute after the meal for a pig switching to the wheat-based diet. (A), milk-substitute group, day -1 ; (B), wheat-based-diet group, day 3. For each functional image, one column of pixels represents one frame with the interpolation and accented edges procedures applied. For details of diets and procedures, see Table 1 and p. 914. The 200 frames obtained during the high-frequency acquisition are plotted side by side to obtain the functional image. A propagated contraction moves the stomach contents up and down resulting in movements of radioactivity up and down. Propagated contractions can be visualized on the functional images by oblique lines of dark pixels $(\rightarrow)$. A fast Fourier transformation enabled determination of the frequency of contractions. Note the increase in propagated contractions with the wheat-based diet on day 3 compared with day -1 .

differences in the volume of test meals or in the energy density $(3.7,4.0$ and $4.2 \mathrm{~kJ} / \mathrm{ml}$ for the barley-based diet, wheat-based diet and milk substitute respectively). Last, the physical form was conserved between the three diets (it can be described as a semi-solid meal). The absence of difference between the physical form of the diets can be confirmed by three arguments: (1) no lag-phase was observed in any of the gastric emptying curves, a feature characteristic of liquid meal (Mayer et al. 1994); (2) no mid gastric band could be detected on any of the scintigraphic images (Moore et al. 1986); (3) the particle size $<1.8 \mathrm{~mm}$ for the barley-based and wheat-based diets meant that was no need for any reduction in particle size before going through the pyloric outlet, unlike thicker food (Meyer et al. 1986).

The differences observed in gastric emptying rates were not related to impaired proximal stomach emptying. In the literature, the relationship between proximal stomach and total stomach emptying is not always straightforward, especially regarding results on the emptying pattern of meals containing different types of fibre. In human subjects, a meal enriched in guar gum accumulated within the upper part of the stomach, unlike a meal enriched in wheat bran. However, no difference in total gastric emptying rate was observed (Rydning et al. 1985). Conversely, again in human subjects, the time for half-emptying of the fundus was not different between a coarse wheat bran- and an ispaghula-enriched meal, but total stomach time for half-emptying of the wheat bran-enriched diet was delayed (McIntyre et al. 1997). In pigs, Guerin et al. (2001) observed numerous backflow episodes from the distal into the proximal stomach with a beet pulp-enriched diet, whereas no such phenomenon was observed with a wheat bran-enriched diet.

While probably not associated with changes in proximal stomach emptying, acceleration of the gastric emptying rate of the wheat-based diet in the first days in our present study appeared to be correlated with changes in corpoantral peristalsis. Indeed, the increased frequency of peristaltic waves moving from the corpus to the antrum on days 1 to 3 with the wheat-based diet may have enhanced the driving force for emptying, assuming antro-pyloroduodenal coordination was unchanged (Mayer et al. 1994). Changes in the antral motility pattern after ingestion of meals enriched with dietary fibre differing in their WHC have been reported in dogs. Guar gum with a high WHC increased the number of isolated contractions, inducing a mixing pattern; wheat bran or cellulose with low WHC increased the number of bursts of propagated contractions, resulting in a propulsive motility pattern (Bueno et al. 1981). In our present study, the wheat-based diet with the lowest WHC induced a propulsive pattern similar to that observed in dogs with wheat bran- or celluloseenriched meals (Bueno et al. 1981), whereas the barleybased diet with a high WHC had no effect on propagated contractions. The WHC variable seems to be a good discriminator to differentiate the two types of fibres chosen in the present study, since our present results are consistent with those of Rainbird \& Low (1986) in young pigs. The addition of wheat bran (low WHC, like our wheat-based diet) to a high-starch meal had no effect on gastric emptying, whereas addition of guar gum (high WHC, like our barley-based diet) increased the retention of the digesta in the stomach (Rainbird \& Low, 1986).

While changes in antral peristalsis induced by the nature of the diets could explain differences in gastric emptying profiles observed initially, they do not explain: (1) why the wheat-based diet lost its stimulating effect on days 4 and 5; (2) why the barley-based diet had a stimulating effect on day 2; (3) why the barley-based diet emptying was delayed on days 4 and 5. Gastric emptying is under a twofold regulation: the gastric 'pump' function itself and nutrient-specific intestinal feedback inhibition and brake mechanisms (Mayer et al. 1994). Since for the cases described earlier (wheat-based-meal emptying on days 4 and 5 and barley-based-meal emptying on days 2 , 4 and 5) the gastric pump functioning does not seem to account for the differences in gastric emptying rate observed, we hypothesized that changes in small intestinal feedback regulation could be involved. Indeed, using the same animal model of dietary switch, we have recently demonstrated that jejunal $\mathrm{Na}^{+}$-dependent glucose absorption is increased $4 \mathrm{~d}$ after the dietary switch to both wheat- and barley-based diets (Boudry et al. 2002). Duodenal and jejunal glucose inhibits gastric emptying in a doseresponse manner (Lin et al. 1989). Glucose absorption via the $\mathrm{Na}^{+}$-glucose co-transporter- 1 is a prerequisite for such an effect (Reybould et al. 1995). From these results, it can therefore be hypothesized that duodeno-jejunal inhibitory feedback towards gastric emptying is enhanced after the 
dietary switch because of increased glucose absorption. Moreover, it can be speculated that since animals were not adapted to the new diets, undigested nutrients could have entered more distal parts of the small intestine. This enhanced flow of nutrients in the ileum could have triggered an ileal brake, also resulting in gastric emptying inhibition (Welch et al. 1988). We can therefore speculate that the normalized gastric emptying at days 4 and 5 with the wheat-based diet is probably the combined result of a stimulation of emptying due to the nature of the dietary fibre on one hand and of an inhibition of emptying due to enhanced intestinal feedback on the other hand. Similarly, delayed gastric emptying with the barley-based diet on days 4 and 5 could originate from enhanced intestinal feedback compared with days 2 or 3 . However, these are only speculations that have to be confirmed experimentally.

In conclusion, we have demonstrated that a dietary switch from milk substitute to a cereal-based diet induced different gastric emptying patterns, depending on the cereal used. While alterations of antral peristalsis seemed to be involved in the differences observed the first $3 \mathrm{~d}$ following the switch, nutrient-specific intestinal feedback or brake mechanisms might explain differences noted during the following days. Independently of the mechanisms involved, the present study showed that the origin of the fibre is critical in the disturbances induced by an abrupt dietary switch and might also have consequences in terms of nutrient absorption and therefore animal growth. Indeed, the relationship between transit time and absorption has been shown to be linear: the longer the transit time, the greater the absorption of nutrients (Huge et al. 1995). It could therefore be argued that nutrient absorption would be greater when pigs are fed a barley-based diet that increases gastric emptying time. In terms of sanitary conditions, the relationship between gastric emptying and diarrhoea is less clear (Levin et al. 1986; Feurle, 1987; Parr et al. 1988; Galil et al. 1993; Charles et al. 1997). However, the common symptom of dumping syndrome, whose pathophysiology involves rapid gastric emptying (Vecht et al. 1997), is diarrhoea. It could therefore be argued that the rapid gastric emptying observed with the wheat-based diet could lead to diarrhoea, as observed when piglets are fed wheat-based diets at weaning (Quemere et al. 1975). Despite the risk of food intake disturbances due to a slow gastric emptying, barley-based diets seem therefore more appropriate for abrupt dietary switch, to maximize nutrient absorption and to avoid diarrhoea.

\section{Acknowledgements}

This work was supported by EC grant Healthypigut no. QLK5-CT2000-00522. The EC is not responsible for the information delivered, which does not represent the opinion of the EC. The authors wish to acknowledge the contribution of P. Touanel, H. Flageul and A. Chauvin for the animal care before and during experimental sessions, and B. Sève for advice in experimental protocol and diet formulation.

\section{References}

Blat S, Guerin S, Chauvin A, Bobillier E, Le Cloirec J, Bourguet P $\&$ Malbert CH (2001) Role of vagal innervation on intragastric distribution and emptying of liquid and semisolid meals in conscious pigs. Neurogastroenterol Motil 13, 73-80.

Bray GA (2002) Afferent signals regulating food intake. Proc Nutr Soc 59, 373-384.

Boudry G, Lalles JP, Malbert CH, Bobillier E \& Seve B (2002) Diet-related adaptation of the small intestine at weaning in pigs is functional rather than structural. J Pediatr Gastroenterol Nutr 34, 180-187.

Bueno L, Praddaude F, Fioramonti J \& Ruckebusch Y (1981) Effect of dietary fiber on gastrointestinal motility and jejunal transit time in dogs. Gastroenterology 80, 701-707.

Castiglione KE, Read NW \& French SJ (2002) Adaptation to high-fat diet accelerates emptying of fat but not carbohydrate test meals in humans. Am $J$ Physiol 282, R366-R371.

Charles F, Phillips SF, Camilleri M \& Thomforde GM (1997) Rapid gastric emptying in patients with functional diarrhea. Mayo Clin Proc 72, 323-328.

Covasa M \& Ritter RC (2000) Adaptation to high-fat diet reduces inhibition of gastric emptying by CCK and intestinal oleate. Am J Physiol 278, R166-R170.

Cunningham KM, Daly J, Horowitz M \& Read NW (1991a) Gastrointestinal adaptation to diets of differing fat composition in human volunteers. Gut 32, 483-486.

Cunningham KM, Horowitz M \& Read NW (1991b) The effect of short-term dietary supplementation with glucose on gastric emptying in humans. Br J Nutr 65, 15-19.

Elashoff JD, Reedy TJ \& Meyer JH (1982) Analysis of gastric emptying data. Gastroenterology 83, 1306-1312.

Englyst HN, Bingham SA, Runswick SA, Collinson E \& Cummings JH (1989) Dietary fibre (non-starch polysaccharides) in cereal products. J Hum Nutr Diet 2, 253-271.

Etienne M, Legault C, Dourmad JY \& Noblet J (2000) Production laitière de la truie: estimation, composition, facteurs de variation et évolution (Milk production in sows: estimation, composition, factors of variation and evolution). In Proceedings of 32ième Journeés de la Recherche Porcine en France, pp. 253-263. Paris: Institut Technique du Porc.

Feurle GE (1987) Pathophysiology of diarrhea in patients with familial amyloid neuropathy. Digestion 36, 13-17.

Galil MA, Critchley M \& Mackie CR (1993) Isotope gastric emptying tests in clinical practice: expectation, outcome, and utility. Gut 34, 916-919.

Guerin S, Ramonet Y, LeCloarec J, Meunier-Salaün MC, Bourguet P \& Malbert CH (2001) Changes in intragastric meal distribution are better predictors of gastric emptying rate in conscious pigs than are meal viscosity or dietary fibre concentration. Br J Nutr 85, 343-350.

Huge A, Weber E \& Ehrlein HJ (1995) Effects of enteral feedback inhibition on motility, luminal flow, and absorption of nutrients in proximal gut of minipigs. Dig Dis Sci $\mathbf{4 0}$ $1024-1034$.

Hurtaud C, Rulquin H \& Verite R (1993) Effect of infused volatile fatty acids and caseinate on milk composition and coagulation in dairy cows. J Dairy Sci 76, 3011-3020.

Johansen HN, Knudsen KE, Sandstrom B \& Skjoth F (1996) Effects of varying content of soluble dietary fibre from wheat flour and oat milling fractions on gastric emptying in pigs. $\mathrm{Br}$ J Nutr 75, 339-351.

Lepionka L, Malbert CH \& Laplace JP (1997) Proximal gastric distension modifies ingestion rate in pigs. Reprod Nutr Dev 37, 449-457.

Levine DS (1986) Delayed gastric emptying and chronic diarrhea 
in a patient with oculodentodigital dysplasia syndrome. J Pediatr Gastroenterol Nutr 5, 329-333.

Lin HC, Doty JE, Reedy TJ \& Meyer JH (1989) Inhibition of gastric emptying by glucose depends on length of intestine exposed to nutrient. Am J Physiol 256, G404-G411.

Linke R, Muenzing W, Hahn K \& Tatsch K (2000) Evaluation of gastric motility by Fourier analysis of condensed images. Eur $J$ Nucl Med 27, 1531-1537.

McIntyre A, Vincent RM, Perkins AC \& Spiller RC (1997) Effect of bran and ispaghula, and inert plastic particles on gastric emptying and small bowel transit in humans: the role of physical factors. Gut 40, 223-227.

Madec F, Bridoux N, Bounaix S \& Jestin A (1998) Measurement of digestive disorders in the piglet at weaning and related risk factors. Prev Vet Med 35, 53-72.

Mayer EA (1994) The physiology of gastric storage and emptying. In Physiology of the Gastrointestinal Tract, pp. 929-976 [LR Johnson, editor]. New York: Raven Press.

Moore JG, Dubois A, Christian PE, Elgin D \& Alazraki N (1986) Evidence for a midgastric transverse band in humans. Gastroenterology $91,540-545$.

Meyer JH, Gu Y, Elashoff J, Reedy T, Dressman J \& Amidon G (1986) Effects of viscosity and fluid outflow on postcibal gastric emptying of solids. Am J Physiol 250, G161-G164.

Noblet J, Fortune H, Dubois S \& Henry Y (1989) Nouvelles Bases des Teneurs en Energie Digestible, Métabolisable et Nette des Aliments pour le Porc (New Basis for Net, Metabolisable and Digestible Energy Content of Foodstuff for Pigs). Paris: INRA Editions.

Parr NJ, Grime S, Brownless S, Critchley M, Baxter JN \& Mackie CR (1988) Relationship between gastric emptying of liquid and postvagotomy diarrhoea. Br J Surg 75, $279-282$.
Quemere P, Bertrand G \& Chauvel A (1975) Utilisation compareé de 3 céréales (orge, blé, mais) par le porcelet sevré précocément (Comparison of three cereals (barley, wheat, maize) by early-weaned piglets). In Proceedings of 7ième Journeés de la Recherche Porcine en France, pp. 217-222. Paris: Institut Technique du Porc.

Rainbird AL \& Low AG (1986) Effect of various types of dietary fibre on gastric emptying in growing pigs. Br J Nutr 55, $111-121$.

Raybould HE \& Zittel TT (1995) Inhibition of gastric motility induced by intestinal glucose in awake rats: role of $\mathrm{Na}(+)$-glucose co-transporter. Neurogastroenterol Motil 7, 9-14.

Rydning A, Berstad A, Berstad T \& Hertzenberg L (1985) The effect of guar gum and fiber-enriched wheat bran on gastric emptying of a semisolid meal in healthy subjects. Scand $J$ Gastroenterol 20, 330-334.

Sève B \& Laplace JP (1975) Influence de la substitution des protéines de lait par des protéines de poisson sur quelques caractéristiques du contenu gastrique chez le porcelet sevré à 12 jours (Influence of substituting milk proteins by fish proteins on some characteristics of gastric contents in piglets weaned at 12 days of age). Ann Zootech 24, 43-57.

Shi G, Leray V, Scarpignato C, Bentouimou N, Bruley des Varannes S, Cherbut C \& Galmiche JP (1997) Specific adaptation of gastric emptying to diets with differing protein content in the rat: is endogenous cholecystokinin implicated? Gut 41, $612-618$.

Vecht J, Masclee AA \& Lamers CB (1997) The dumping syndrome. Current insight into pathophysiology, diagnosis and treatment. Scand J Gastroenterol 223, 21-27.

Welch IM, Cunningham KM \& Read NW (1988) Regulation of gastric emptying by ileal nutrients in humans. Gastroenterology 94, 401-404. 